\title{
Principii misionare în opera filosofului creştin Nichifor Crainic
}

\author{
Emanuel Ioan CĂŞVEAN*
}

Abstract: Principles missionary in Christian philosopher Nichifor Crainic's opera. In this study, the author presents the main elements that characterize the missionary concept, of the great theologian and philosopher interwar Nichifor Crainic, analysing both his philosophical work, the poetic and theological, widespread both in antum or postum published volumes pages as well as pages of magazines Gândirea, Vremi, Ramuri, Transylvania etc. Unlike quasi-known missionary conceptions of Eastern theology, Crainic concept approach is distinguished both by its originality as well as through the way in which the author correlates with the patriotic Christian principles, foot printed without falling into filets, with the Christian ideal and national feeling. Rid of the some contrasting attitudes of the controversies that have generated both actions as well as some of his ideas, author researched opera proves equally prodigious through stretch and content, and harnessing its emphasis is

\footnotetext{
* PhD candidate, Faculty of Orthodox Theology at University „Babeş-Bolyai", Cluj-Napoca, Romania.
} 


\section{Emanuel Ioan CĂȘVEAN}

very profitable for Romanian Orthodox theology. Therefore, the present research, which proposes a new approach, comparing his opera with critical opinions about it, is meant to be both a tribute to the great author and a fruitful and useful research, that adheres to the theme proposed in this year by the Holy Synod of the Romanian Orthodox Church, having multiple practical applications.

Keywords: mission, etnocracy, philosophy, ortdodox mistique.

A scrie astăzi despre Nichifor Crainic este o adevărată provocare pentru orice autor. Personalitatea controversată a filosofului şi poetului interbelic, criticată de unii, elogiată într-o manieră aproape encomiastică de alţii, privită cu rezerve de alţii sau chiar ignorată², suscită astăzi, în ciuda multiplelor abordări existente,

${ }^{2}$ Cf. Geta Marcela Pârvulescu, Nichifor Crainic- monografie, Deva, Editura Emia, 2010; Stelian Spânu, Nichifor Crainic - lumini și umbre, București, Editura Saeculum Vizual, 2013; Răzvan Codrescu, Nichifor Crainic - schiță de portret, în rev. „Tabor”, anul III, nr. 10, Ianuarie, 2010, pp. 81-86; Laura Bădescu, Observații asupra autocenzurii în totalitarism. Cazul Nichifor Crainic, în rev. „Tabor”, anul III, nr. 10, Ianuarie, 2010, pp. 71-76; Cristian G. Romocea, ChurchState Relations in Post-1989 Romania, în rev. ,Journal of Church and State”, no. 53 (2), Spring, 2011, pp. 269-270; Keith Hitchins, Historiography of the Countries of Eastern Europe: Romania, în „The American Historical Review”, Vol. 97, No. 4, October, 1992, p. 1074; Roland Clark, Orthodoxy and nationbuilding: Nichifor Crainic and religious nationalism in 1920s Romania, în rev. „Nationalities Papers”, vol. 40, No. 4, July, 2012, p. 525; Eugen Lovinescu, Istoria literaturii române contemporane (1900-1937), Bucureşti, Editura Librăriei Socec, 1937, pp. 92-93; Lucian Vasile Bâghiu, Tudor Arghezi și Valeriu Anania, în rev. „Philologica Jassyensia”, An VI, Nr. 2 (12), 2010, p. 7; ElenaIrina Ancuța, Nichifor Crainic - teolog și imnolog al neamului românesc, în rev. „Studii de știință și cultură”, anul V, nr. 4 (19), Decembrie, 2009, p. 50; Mihaela Albu, Dialogul știință-religie oglindit în literatura română (poezia Gândirii: intre incifrare și revelație), în rev. „Studii de știință și cultură”, anul V, nr. 4 (19), Decembrie, 2009, p. 90; Ov. S. Crohmălniceanu, Literatura română între 
interesul teologilor, istoricilor, filologilor şi mai ales a teologilor şi acest lucru, pe de-o parte datorită operei sale vaste, antologizată în parte în diferite volume încă din timpul vieţii operei, şi apoi, în lucrări antume $^{3}$, sau presărată în paginile unor periodice precum Gândirea ${ }^{4}$, Neamul Românesc ${ }^{5}$ sau Ramuri $^{6}$, pe de altă parte datorită rolului jucat

cele două războaie mondiale, vol. II, Bucureşti, Editura Minerva, 1974, p. 311; Călin Sărmăghițean, Forma poetică a dogmei la Nichifor Crainic - o încercare de aplicare a perspectivei lui E. Coşeriu asupra limbajului poetico-teologic şi asupra modalității de exprimare a dogmei creştine, în rev. „Antropomedia”, nr. 2, 2010, p. 54; Laura Bădescu, Retorica poeziei religioase a lui Nichifor Crainic, col. „Universitas”, Bucureşti, Editura Minerva, 2000. Acestora se adaugă şi anumite evocări din opere literare. A se vedea, de exemplu: Virgil Gheorghiu, Condotiera, trad. Georgiana Matei, Cluj-Napoca, Editura Renaşterea, 2011, unde autorul îl descrie sub chipul poetului Ovid Panteleimon pe poet, într-o manieră de-a dreptul romantică.

${ }^{3}$ Ca de exemplu: Nichifor Crainic, Poezii, ed. Aureliu Goci, Bucureşti, Editura Gramar, 1998; Idem, Poezii alese 1914-1944 - în selecția autorului, Bucureşti, Editura Roza Vânturilor, 1990; Idem, Soim peste prăpastie. Versuri inedite create în temnițele Aiudului, ed. Nedic Lemnaru, Bucureşti, Editura Roza Vânturilor, 1990. Precum: Idem, Tara de peste veac. Poezii antume (1916-1944), ed. Ioan Cracă, București, Editura Eminescu, 1997; Harry Brauner, Melodii compuse in temnițele Aiudului pe versuri de Mihai Eminescu, Șt. O. Iosif, Al. Macedonski, Tudor Arghezi, Elena Farago, Rainer Maria Rilke, Nichifor Crainic, Bucureşti, Editura Ars Docendi, 1999, pp. 24-31; Ioana Cistelecan, Antologia poeziei carcerale, Cluj-Napoca, Editura Eikon, 2006; Cf. Ion Buzași, Poezia religioasă românească, Ediția a II-a, Cluj-Napoca, Editura Dacia XXI, 2011, pp. 153-180. ${ }^{4}$ Pentru o prezentare amplă a publicisticii crăinicene în paginile acestui periodic cultural, la a cărui fondare a contribuit filosoful şi căreia i-a fost vreme de mai mulţi ani redactor - şef, atât în varianta clujeană, cât şi în cea bucureşteană, a se vedea: Emil Pintea, Gândirea (1922-1944). Indice bibliografic adnotat, ClujNapoca, Editura Echinox, 1998.

${ }^{5}$ Nichifor Crainic, Cântece evanghelice, în rev. „Neamul românesc”, anul XIII, nr. 27, 28 Ianuarie, 1918, p. 1; Idem, Cântec evanghelic, în rev. „Neamul Românesc", anul XIII, nr. 17, 18 Ianuarie, 1918, p. 1.

${ }^{6} \mathrm{Cf}$. Idem, În mine nu e Dumnezeu, în rev. „Ramuri - Drum drept”, anul XV, nr. 25, 18 iunie, 1922, p. 35. 
în peisajul cultural, social şi politic al perioadei interbelice, iar pe de altă parte, datorită caracterului şi a personalităţii lui complexe şi a atitudinilor sale.

În acest context, abordarea de faţă îşi propune să analizeze felul în care se interferează filosofia, teologia, cu precădere cea mistică, dar şi cea dogmatică, cea liturgică, filologia şi filosofia în opera şi viaţa personajului cercetat, pentru a manifesta un buchet autentic de elemente ale misiunii creștine. Lucrarea se doreşte o scurtă analiză în mentalitatea crăineană și interferența cu spațiul misionar extrem de autentic al personajului studiat, realizând o analiză complexă şi echilibrată prin care sunt valorificate ideile importante şi actuale din opera filosofului.

Într-una din multele biografi ale lui Nichifor Crainic, - e vorba de cea realizată de Stelian Spânu ${ }^{7}$ - autorul plasează momentul nașterii filosofului Nichifor Cranic, într-un cadru armonic al celor 2 spații de conjugare ale satului de câmpie, teluric și celest, într-o manieră aproape mantrică, inducând în atenția cititorului, o metodă fie retrospectivă - atunci când arta analitică este adică descendentă, însă păstrează ca un bloc monolit traiectul plenar al carierei lui Nechifor Crainic, fie introspectivă atunci cand face o aprofundare a traiectoriei sale prin intermediul timpului prezent pentru a descrie emoția trăirii evenimențiale. În acest context extrem de bine construit Stelian Spânu plasează momentul nașterii și al inițierii baptismale a pruncului Ion - viitorul Nichifor Crainic, într-un spațiu ancestral emanat de protecția de factură profetică a Botezătorului, ca primă axă a propovăduirii dar și a suferințelor care nu-l vor ocoli toată viața ${ }^{8}$, deci o moștenire ancestrală a unei lumi idilice a spațiului domestic românesc care îl va însoți pe întreg parcusul devenirii sale.

Fără a face o incursiune biografică atent selecționată, se impune

\footnotetext{
${ }^{7}$ Stelian Spânu, Nichifor Crainic lumini și umbre, o biografie. București, Editura Saeculum Vizual, 2013, p. 7.

${ }^{8}$ Ibidem, p. 7.
} 
o primă mențiune biografică, pe care o deducem din lecturarea memoriilor sale, aceea a luptei cu săracia mistică a locurilor natale care alături de penuria generalizată a satelor de câmpie au determinat o fantastică mobilizare în a depăși condiția de rob al pământului pentru a-și ajuta familia și frații. Observăm ca mecanism interior, o dorință lăuntrică de depășire - însă nu de negare - a condiției sale, fapt care va postula întreaga sa operă și trăire în noile direcții pe care viața sa le va experimenta. Deasemeni o direcție extrem de importantă a maturizării intelectuale va fi determinată de refugiul în spațiul teologiei, care îi va deschide apetența pentru frământările epocale ale românismului ${ }^{9}$ și ale creștinismului precum și filosofia, metafizica și mai apoi mistica.

Apetența literară a tânărului pentru decodarea contextelor politico-culturale ale vremii, învăluite în cenzură si irațional îl vor conduce într-o zonă de căutare continuă a manifestării libertății spirituale aplicată în gravitarea în jurul axei credinței strămoșești ca izvor al unei mesianități ce putea decoda iraționalul cotidian. E o primă formă de conturare a dialecticii sale misionare care îi va însoți zona de confort intelectual prin temele majore ale filosofiei crăiniene. Simpla utilizare a pseudonimului literar acela de Nichifor - (neke-phoros) ne induce ideea de luptă mitologică mesianică pentru conservarea valorilor autohtone ale ethosului logosic. Stelian Spânu ne oferă o informație inedită conform căreia pseudonimul său se inspiră din numele unui patriarh bizantin $(808-815)^{10}$ care a fost exilat pentru suportul său acordat călugărilor studiți. Demn de menționat e faptul că el se va mișca într-o zonă a căutărilor interioare, a tensiunii de reunificare a spiritului național pornind de la poezie până la libertarea politică, iar apoi a unei axiologii filosofice care să-i

\footnotetext{
${ }^{9} A$ se vedea descrierea pe larg a tensiunilor pe care tânărul Ion Dobre, le trăise în tinerețea sa, în plină formare culturalo-politică, expusă în lucrarea lui Stelian Spânu, op. cit., p. 34.
}

${ }^{10}$ Ibidem, p. 34. 
poată împăca setea după transcendent postulate în începuturile școlii de teologie interbelice caracterizate printr-o sete a cunoașterii divine.

Odată cu perspectiva absolvirii cursurilor Seminarului Central aparte și perspectiva abordării tot mai serioase a unei vocații sacerdotale, însă pe care o va abandona în detrimentul cercetării teologice și a creației literare.

Din vasta sa biografie deducem o uriașă forță de emancipare teologică pe care o putem traduce în aria imboldului misionar, datorită unei atitudini de protest pe care tânărul teolog o resimțea față de sistemul defectuos care nu-i putea satisface setea după absolut sau elucidarea unor lispuri ale teologiei academice care părea cam stearpă din punct de vedere al aplicabilității, generându-i acestuia nenumărate crize teologice. Teologia de școală se afla în faza pioneratului, fiind incapabilă în a elucida unele aspecte ale dogmelor și ale spiritualitătii ortdodoxe $^{11}$. Demn de remarcat în ceea ce privește puterea iradiantă a unui cartcter misionar manifestat polivalent a tânărului teolog, e capacitatea de critică a Teologiei nu ca fenomen sau stare, ci ca și convenție academică.

După plecarea lui Nichifor Crainic la Viena traiectoria publicitică a acestuia se va amplifica în primul rând datorită noilor sale prietenii pe care le va lega cu Blaga, Cezar Petrescu și alții, urmând ca interesul publicistic al acestuia să graviteze înspre o spiritualitate autohtonă a satului cu impact misionar care este abia la începutul dezvoltării sale. În rândurile primelor numere ale Gândirii el va adopta o atitudine tranșantă vis-a-vis de orientarea către Occident care e păguboasă nu doar din punct de vedere spiritual ci și politic pentru că susține el această optică eurofilă e o reîntoarcere a Romei antice cu năravurile specifice, - văzute ca filosofie nu ca explorare pragmatică a tehnicii,- în detrimentul tradiționalismului autohton ${ }^{12}$. Ce e interesant

\footnotetext{
${ }^{11}$ Ibidem, p. 45.

${ }^{12}$ A se vedea atitudinea agresivă pe care o îmbrățisează în primele numere ale Gândirii (II-VI) din 1923.
} 
de analizat e reproducerea mentală a paternului apologetic dintre luptele răsăritului ortodox cu occidentul păgân ale epocii primare, e tot $\mathrm{o}$ atitudine misionară extremă de rezistentă împotriva ideologiilor reformatoare ale unei europe fragile din punct de vedere politic și religios care putea aduce simptomul unei îmbolnăviri a autohtonului care se putea pierde.

Pentru Nichifor Crainic ortodoxia se pierde în neamul românesc, de fapt se identifică ,În neamul acesta ... todeauna a dominat o conștință religioasă ortodoxă ${ }^{\prime \prime 13}$.

Impactul misionar pe care îl aduce cu pasiune reprezintă tranziția dinspre aria patriotismului înspre zona spiritualității care deschide în istoria literaturii române o nouă direcție de abordare ${ }^{14}$.

E de fapt în optica lui Spânu, o argumentare a esteticii naționale care își conservă sentimentul religios și bogăția spirituală, iar rolul decisiv în această abordare îl ocupă Biserica străbună care pentru el era „substanța amestectă pretutindeni cu substanța etnică ${ }^{\prime \prime}$. El va critica pe parcursul activității sale gândiriste și dedublarea țăranului român care nu practica viața sacramentală a bisericii străbune în detrimentul unui misticism de factură păgână care e păgubos pentru etosul neamului. Se realizează astfel delimitarea celor 2 paradigme în jurul cărora gravitează țăranul român - zona tradițional autentică și spațiul vulnerabil al împrumuturilor de altă factură decât spiritualitatea autentică, transformându-l pe Crainic în ideologul ortodoxismului și

${ }^{13}$ Ibidem, p. 45.

${ }^{14}$ De exemplu în ,Între Apollo și Iisus”, în rev. Gândirea, anul VII, nr. 1, Ianurarie, 1927, pp. 1-4, realizează o paralelă între filosofie și teologie pornind de la tabloul lui Max Klinger, Iisus în Olimp (tablou cu conținut sincretist) prin care arată că creștinismul dă un nou sens și o nouă formă artei, ca şi în „Teologie și estetică”, anul XVIII, al Gândirii nr. 4, Aprilie, 1939, pp. 204210. Va dezbate argumentarea acestei legături dintre artă și teologie văzută nu ca cenzură ci ca împlinire a vocației latreutice. Cf. Gândirea, anul XVI, nr. 1, Ianuarie, București, 1937, pp. 1-9.

${ }^{15}$ Stelian Spânu, op. cit., p. 10. 


\section{Emanuel Ioan CĂȘVEAN}

al statului etnocratic ${ }^{16}$. De aici până la anumite derapaje regretabile ulterior, pe scara viziunii politice dar și a polemizărilor nefecunde nu a fost decât un mic pas pe care Crainic 1-a facut în căutarea de fapt a unui sistem de valori spirituale absolute în ecuația unei filosofii politice inexacte a epocii respective. Lupta sa ideologică a fost mereu în răspândirea unui adevăr unic și a unei filosofii evanghelice cu aplicabilitate în aparatul de stat - a se vedea optica sa în ortodoxie și etnocrație - care nu făcea altceva decât să întărească analiza religioasă a lucururilor, deci efectele spritului misionar. Această doctrină politică o va intitula naționalism creștin. Ce e interesant de analizat e cadrul de la care el pleacă, acela al utopicului de factură mioritică ajungând la una din tezele generale și consacrate ale teologiei - în Nostalgia Paradisului prin evocarea temei dionisiane a frumosului care se identifică cu Creatorul, de unde putem induce raportul extrem de strâns, de-a dreptul organic între teologie si cultură între simtomul extern al teologiei (prin spațiul misionar) și fiecare sector al istoriei. Vastele sale analize ale contextelor politice externe cât și cele interne ascund în interiorul său o vastă viziune misionară desfășurată atât $a d$ intra cât și ad-extra.

Pentru Crainic problematica teologică nu ține de spaţiul privatului, al eului interior, ci devine în mod ontologic o dezbatere descărcată pe arena publică. Evident linia misionaraă pe care acesta o adoptă și generează de bună seamă e una extremă în care metodologia analitică de factură filosofică parcă adumbrește pe alocuri spațiul revelației, așa se explică anumite derapaje ale acestuia de genul elogiilor aduse lui Hitler și Musollini, în care el vedea 2 salvatori de factură mesianică și combatanți ai filosofiei marxiste, devenind prizonierul propriilor iluzii ${ }^{17}$.

Arta sa poetică găzduiește aceeași preocupare pentru conservarea autenticului pe care acesta îl traduce în terminologia

\footnotetext{
${ }^{16}$ Ibidem, p. 67.

${ }^{17}$ Ibidem, p. 75.
} 
spiritualității pe care adesea o descrie prin imagini extrem de reale uneori chiar de factură rațională, iar alteori prin exersarea unui instinct intuitiv al misterului, care evident depășește granița rațiunii adevărului religios ${ }^{18}$.

Ortodoxismul său românesc este în poezia lui o realitate aievea, în care se îmbină linia ondulată a spațiului ,,mioritic” cu condiția creștină a mântuirii. $N u$ e o intâmplare că el este doctrinarul și teoreticianul ortodoxismului, in conștința lui poetică, mai mult ca în oricare alta, peisajul și permanența istorică s-au oglindit cu putere originală (...) nu e doar o funcție istorică pe care biserica a jucat-o pe aceste meleaguri ci identificarea unor categorii psihice proprii spațiului românesc, o integrare a datelor psihismului autohton in viziunea spiritului românesc, (...) în viziunea creștină a cosmosului (...) despre realitățiile metafizicii creștine ${ }^{19}$ prin care esteticul și religiosul se identifică ${ }^{20}$.

În sensul celor menționate mai sus se poate afirma că cea mai mare contribuție pe care o aduce misiunii creștine vis-a-vis de cultura spiritualității de la noi, constă în linia teologică pe care o va descoperi la Viena și pe care o va implemeta cu greu la noi prin viitoarele cursuri de Teologie Mistică, pornind de la Dionisie, Maxim și Ioan Dmaschinul. El vede în această disciplină exact ceea ce lipsea teologiei românești acelei perioade, în care teologia de școală manifesta un blocaj prin lipsa ethosului interior, o fisură între mesaj și persoană, defapt o greutate a aplicabilității spirituale. Teologia fără mistică nu e decât o erudiție stearpă care duce la acumulare de cunoștințe și nu la trăirea ortodoxiei ${ }^{21}$. Crainic face o delimitare în această nouă abordare academică între patrologie și scolastică, accentuând măreția și complexitatea teologiei mistice căreia îi va înființa la București în anul 1932 o catedră ce va purta numele de Teologia Ascetică și Mistică.

\footnotetext{
${ }^{18}$ Nihifor Crainic, Poezia noastra religioasă, Giurgiu, Editura Episcopoiei Giurgiului, 2010, p. 11.

${ }^{19}$ Ibidem, p. 13.

${ }^{20}$ Ibidem, p. 20.

${ }^{21}$ Stelain Spânu, op.cit, p. 203.
} 
Prelegerile și meditațiile ulterioare susținute în cadrul facultății de teologie vor problematiza aspectele esențiale ale acestei noi orientări în zona teologiei în care pornid de la scrierile patristice și scolastice va accentua deschiderea pe care aspectul supranatural îl constituie în vederea desăvârșirii. Aici se deduc câteva din exigențele extrem de clare ale misiunii prin predicarea evanghelică a izvoarelor misticii (scriptura și tradiția) precum și transmiterea nealterată a conținutului scaramental prin trimiterea directă la zona scrierilor patristice pentru edificarea mentală și spirituală a corpusului ecleziastic (și a societății).

Prin asumarea unui apostolat din popularizarea misticii teologice defapt Crainic deschide aclimatizarea teologiei românești cu marele corpus filocalic care încă nu era tradus în întregime ori cunoscut larg de către cultura teologică și profană. El poartă prin corespondență de pildă cu L.Blaga, discursul misionar de prezentare în termenii nostalgiei, a filocaliei românești care chipurile exista tradusă de 150 de ani, dar care nu era accesibilă rămând îngropată precum o nestemată. Tot Blaga îi recunoște meritul lui Crainic de a realiza o teorie a culturii, ce poate fi atacabilă la nivel filosofic însă care rezistă admirabil din punct de vedere teologic ${ }^{22}$. Deschiderea teologică crăineană nu se limitează doar la o direcție monovalentă a depozitarului misionar autohton răsăritean ci depășește granițele ecumenice prin abordarea unei teologii comparate, prin aprofundarea misticii germane a lui Ekhart, prin activiatea publicistică în Clutura Creștină de la Blaj etc.

Cert e că valoarea și importanța prodigioasei opere crăiniene constă tocmai în simbioza evidentă a sensibilității teologice care cuprinde întreaga sa preocupare intelectuală manifestată pe parcursul întregii sale opere într-un apostolat laic, o împlinire a unei misiuni de sacerdot universal al Logosului, care își merită în ciuda anumitor derapaje meritul printre marile spirite misionare universale.

Cea mai efervescentă parte a materialelor ce poartă semnătura

${ }^{22}$ Ibidem, p. 209. 
lui Crainic o constiutie articolele ce conțin atitudini ale autorului cu privire la anumite probleme culturale sau sociale ce frământau societatea vremii sale ${ }^{23}$, întărind o formă personalizată a unui misionarism asumat la nivel social, dimensiune sine qua non a profilului omului de cultură.

\section{Bibliografie}

1. Albu, Mihaela, Dialogul știință-religie oglindit în literatura română (poezia Gândirii: între încifrare și revelație), în rev. „Studii de știință și cultură”, anul V, nr. 4 (19), Decembrie, 2009.

2. Ancuța, Elena-Irina, Nichifor Crainic - teolog și imnolog al neamului românesc, în rev. „Studii de știință și cultură”, anul V, nr. 4 (19), Decembrie, 2009.

3. Bădescu, Laura, Observații asupra autocenzurii în totalitarism. Cazul Nichifor Crainic, în rev. „Tabor”, anul III, nr. 10, Ianuarie, 2010.

4. Idem, Retorica poeziei religioase a lui Nichifor Crainic, col. „Universitas”, Bucureşti, Editura Minerva, 2000.

5. Bâghiu, Lucian Vasile, Tudor Arghezi și Valeriu Anania, în rev. „Philologica Jassyensia”, An VI, Nr. 2 (12), 2010.

6. Brauner, Harry, Melodii compuse în temnițele Aiudului pe versuri de Mihai Eminescu, St. O. Iosif, Al. Macedonski, Tudor Arghezi, Elena Farago, Rainer Maria Rilke, Nichifor Crainic, Bucureşti, Editura Ars Docendi, 1999.

7. Clark, Roland, Orthodoxy and nation-building: Nichifor Crainic and religious nationalism in 1920s Romania, în rev. „Nationalities Papers", vol. 40, No. 4, July, 2012.

8. Codrescu, Răzvan, Nichifor Crainic - schiță de portret, în rev. „Tabor”, anul III, nr. 10, Ianuarie, 2010.

9. Crainic, Nichifor, Poezii, ed. Aureliu Goci, București, Editura Gramar, 1998.

10. Idem, Poezii alese 1914-1944 - în selecția autorului, Bucureşti, Editura Roza Vânturilor, 1990.

${ }^{23}$ Maxim Morariu, Nichifor Crainic și Gândirea, în „Tabor”, anul IX, nr 3. Martie, 2015, p. 31. 
11. Idem, Soim peste prăpastie. Versuri inedite create în temnițele Aiudului, ed. Nedic Lemnaru, Bucureşti, Editura Roza Vânturilor, 1990.

12. Idem, Țara de peste veac. Poezii antume (1916-1944), ed. Ioan Cracă, București, Editura Eminescu, 1997.

13. Idem, Intre Apollo și Iisus, în rev. „Gândirea”, anul VII, nr. 1, Ianurarie, 1927.

14. Idem, Poezia noastra religioasă, Giurgiu, Editura Episcopoiei Giurgiului, 2010.

15. Crohmălniceanu, Ov. S., Literatura română între cele două războaie mondiale, vol. II, Bucureşti, Editura Minerva, 1974.

16. Gheorghiu, Virgil, Condotiera, trad. Georgiana Matei, Cluj-Napoca, Editura Renaşterea, 2011.

17. Hitchins, Keith, Historiography of the Countries of Eastern Europe: Romania, în „The American Historical Review”, Vol. 97, No. 4, October, 1992.

18. Lovinescu, Eugen, Istoria literaturii române contemporane (19001937), Bucureşti, Editura Librăriei Socec, 1937.

19. Morariu, Maxim, Nichifor Crainic și Gândirea, în „Tabor”, anul IX, nr 3. Martie 2015.

20. Pârvulescu, Geta Marcela, Nichifor Crainic - monografie, Deva, Editura Emia, 2010.

21. Romocea, Cristian G., Church-State Relations in Post-1989 Romania, în rev. „Journal of Church and State”, no. 53 (2), Spring, 2011.

22. Sărmăghițean, Călin, Forma poetică a dogmei la Nichifor Crainic - o incercare de aplicare a perspectivei lui E. Coşeriu asupra limbajului poetico-teologic şi asupra modalității de exprimare a dogmei creştine, în rev. „Antropomedia”, nr. 2, 2010.

23. Spânu, Stelian, Nichifor Crainic - lumini și umbre, București, Editura Saeculum Vizual, 2013. 